\title{
Monetary policy effect in an economy with heav- ily managed exchange rate
}

\author{
BUI THANH TRUNG \\ University of Economics HCMC - trungbt@ueh.edu.vn
}

\begin{abstract}
ARTICLE INFO ABSTRACT
\end{abstract}
Article history:

Received:

Nov. 15, 2016

Received in revised form:

Mar. 13, 2017

Accepted:

Mar. 31, 2017

Keywords:

Sign restriction

Monetary policy

Exchange rate

Fixed exchange rate
The primary objective of this paper is to investigate the effect of monetary policy on macroeconomic variables in Vietnam, which is a small, open, and developing economy with heavily managed exchange rate. Monetary policy shock is identified by the sign restriction methodology. Unlike previous studies, this paper identifies a monetary contraction by a combination of an increase in interest rates, a decrease in central bank credit, a drop in the stock of foreign exchange reserves, and a fall in broad money. The empirical results show that output and prices begin to reduce after a restrictive monetary shock in the medium term, suggesting the adverse effect of monetary policy in the short term and the necessity to improve the transparency of monetary setting. Meanwhile, exchange rates are unresponsive to a tightening decision, which is not a sign of puzzle but plausible when the nature of a peg regime is taken into account. Furthermore, foreign exchange policy causes inflation to rise since its effect is partially sterilized by changes in monetary policy instruments. Therefore, Vietnamese monetary authorities should consider a shift toward a more floating regime to achieve monetary independence or foster the development of financial markets in order to alleviate inflationary pressure caused by foreign exchange policy. 


\section{Introduction}

An enormous number of empirical studies have emphasized the importance of exchange rate channel in the conduct of monetary policy in developed countries with the flexible exchange rate regime. In those studies, monetary policy was widely defined as shocks to either interest rates or money aggregates. However, for a small and open country, it is suggested that monetary policy should be defined in a different way such as the spread between interbank interest rates and the exchange rate depreciation ratios for Turkey (Berument, 2007) or a combination of positive shocks to interbank interest rate and negative shocks to foreign reserves for Taiwan (Ho $\&$ Yeh, 2010). The identification problem also emerges in Vietnam, of which the gross domestic product is much lower than that of both Turkey and Taiwan and exchange rates are heavily managed just like Taiwan. Compared to Taiwan, the money market in Vietnam is underdeveloped, and thus monetary policymakers have little control over short-term interest rates. Consequently, they manipulate policy rates in order to increase or decrease market interest rates, providing credit for certain banks directly through the purchase of short-term securities and even long-term securities in emergent situations. Furthermore, since the economy mainly accentuates exporting activities, central bankers frequently intervene to stabilize exchange rates in the foreign exchange market, which is essential for exporting enterprises to maintain the stability of revenues and incurred costs. Taken as a whole, the setting of monetary policy is necessarily identified by changes in four variables such as policy rates, central bank credit, the stock of foreign reserves, and broad money rather than movements in only short-term interest rates or money supply.

Given empirical estimations, the literature suggests several approaches to examine the effect of monetary policy. First, the recursive VARs were used in numerous studies, of which the notable ones are Sims (1992) and Berument (2007). However, plausible results have been provided in analyzing a relatively close and large economy such as the United States (Kim \& Roubini, 2000; Ho \& Yeh, 2010). In case of a small and open economy, it is suggested to employ the non-recursive methodology to account for instantaneous reactions of monetary policy instruments to macroeconomic shocks (Kim \& Roubini, 2000). Ho and Yeh (2010), on the other hand, adopted sign restriction methodology to investigate the monetary policy transmission in such a fixed-exchange rate economy as Taiwan. 
This paper also employs the sign restriction methodology for the identification of monetary policy in Vietnam, which is a small open economy with heavily managed exchange rate. Unlike Ho and Yeh (2010), this paper associates a contractionary monetary shock with a rise in policy rates and a fall in broad money, central bank credit, and foreign exchange reserves. In the language of sign restriction, a monetary contraction does not cause a decrease in policy rates and does not lead to an increase in broad money, central bank credit, and foreign exchange reserves. No restrictions are imposed on economic variables such as output, prices, trade balance, and exchange rates because the main focus of this paper is to analyze whether and how these variables react to monetary policy shocks. Furthermore, unlike other central bankers, monetary authorities in Vietnam focus more on fostering economic growth as directed by the government and have neither explicit nor implicit target for price stability. Therefore, it is important to answer the question as to whether monetary policy contraction is effective in controlling output and inflation in the case of Vietnam.

The rest of the paper is organized as follows. Section 2 provides an in-depth review about the role of exchange rates in the conduct of monetary policy in a small and open economy as well as a range of methodologies to solve the emerging puzzles. Section 3 presents a discussion of sign restrictions VAR, the identification of monetary policy, and the description of the data used. Section 4 discusses empirical results. Finally, Section 5 concludes the paper and suggests implications.

\section{Literature review}

\subsection{Exchange rate channel and mac- roeconomic variables}

Since the world is more integrated and the number of countries adopting the flexible exchange rate regime is increasing, it is argued that economists should place a greater emphasis on the exchange rate channel in monetary policy transmission (Mishkin, 2013). This channel works mainly through the interest rate effect, whereby a rise in real domestic interest rate increases the relative attraction of domestic assets, thereby leading to an appreciation of domestic currency. As a result, domestic goods become more expensive than foreign goods, which reduces net export (export minus import), and thus economic activities are decreased.

Another theoretical framework, which has been extensively cited in the literature, is the overshooting hypothesis proposed by Dornbusch (1976). The theory accounts for the existence of price stickiness and 
thus shows comparative advantage to capture the significance of exchange rate channel in small, open, and developing countries. Accordingly, following an increase in domestic interest rates, nominal exchange rates initially appreciate due to the existence of price stickiness, and then depreciate, consistent with the theory of uncovered interest parity. In detail, as central bankers tighten the monetary policy by either increasing interest rates or reducing money supply, the health of the domestic economy becomes worse with a rise in funding costs, transaction costs, and information costs. Meanwhile, enterprises cannot immediately change quoted prices for goods and services, thereby posing a sluggish change in the price level. On the contrary, currency markets are more liquid, and prices change with higher frequency. For those reasons, a contractionary monetary shock causes an immediate rise in real interest rates, which leads to greater demands for domestic assets and an impact appreciation of domestic currency. Once domestic currency is overvalued, market expectation shifts and a depreciation is likely to occur. In summary, a monetary contraction leads to an impact appreciation and a subsequent depreciation.

However, empirical findings seem contrary to the popular belief, which demonstrates puzzling responses of macroeconomic variables, especially exchange rates, to monetary policy shocks. The first puzzle is exchange rate puzzle, in which exchange rates show a depreciation (rather than an appreciation) after a contraction in monetary policy (Sims, 1992; Grilli \& Roubini, 1995, 1996). The second puzzle appears when exchange rates do appreciate after a contractionary shock, but the appreciation lasts for a prolonged period of up to three years (Clarida \& Gali, 1994; Grilli \& Roubini, 1995, 1996; Kim, 2001, 2005). Therefore, exchange rates have a hump-shaped curve in response to a contraction in monetary policy, which violates the theory of uncovered interest parity. Economists have widely termed the phenomenon as delayed overshooting puzzle.

Solving puzzling responses of exchange rates to monetary policy shocks

The monetary policy transmission has been widely investigated by using either recursive, structural (zero restriction), or sign restriction VARs. The recursive version was employed in many studies but their estimations were, to large extent, contrasting with conventional theories. Using this approach for five large industrial countries, Sims (1992) argued that the exchange rate puzzle could be resolved by using short-term interest rates as an indicator of monetary policy. Although his empirical results seemed reasonable, several puzzles emerged such as persistent ap- 
preciation for France and Japan or persistent depreciation for Germany. Similarly, Grilli and Roubini (1995) employed this approach but with a different identification of monetary policy - the differential between domestic and foreign interest rates. They analyzed the puzzling responses of exchange rates for non-US G7 countries, showing an extended period of (rather than temporal) appreciation after a monetary contraction.

As suggested by Sims (1992), many studies have added more shocks such as commodity prices to VAR models to capture the rich pool of information monitored by central bankers, but the efficiency of this approach was rather limited. A few studies made a further effort by introducing factors indicating general concepts like "economic activities." Although such large-scale VARs show advantages in solving puzzles, it seems feasible for the analysis of developed countries where fundamental statistics are adequate and well managed. By contrast, a dearth of data forces studies on this field to rely on smallscale VARs in the context of developing countries.

Another explanation for the inefficiency of the recursive VARs in solving puzzling outcomes of monetary policy is the likely simultaneity between exchange rates and interest rates in small and open countries. In such cases non-recursive
VARs are more suitable. Cushman and Zha (1997) employed this approach when studying Canada, which is considered a small economy in comparison with the United States. They assumed that the central bank quickly responds to concurrent shocks in financial variables and found no puzzling interaction between money supply, interest rates, and exchange rates. Kim and Roubini (2000) further developed the identification of Cushman and Zha (1997) to capture the openness of a small economy. They argued that short-term interest rates change quickly in response to innovations in macroeconomic variables such as money stock, world oil prices, and exchange rates. Therefore, no restrictions are imposed on these variables in the structural VAR model.

The sign restriction technique is another approach used to solve exchange rate anomalies in a small and open country. Uhlig (2005) adopted this methodology to identify monetary policy shocks in the United States. Accordingly, a contraction was defined by an increase in federal fund rates in association with a reduction in non-borrowed reserves and a decline in price levels. The sign restriction on prices was due to the adoption of an inflation targeting policy. The author found that a contraction led to a fall in output in the short run. For Russia, Granville and Mallick 
(2010) emphasized the importance of exchange interventions in an economy with managed floating regime and examined whether such interventions affected the economic performance and price stability. They imposed sign restrictions on selected variables to define exchange rate shocks as well as inflation-targeting shocks, finding that the former shocks exercise relatively strong impact on inflation. Rafiq and Mallick (2008) investigated three strong economies in Europe, including German, Italy, and France. To define the stance of monetary policy they introduced sign restrictions to four variables: narrow money, exchange rates, interest rates, and inflation (the first two characterize the openness nature of these economies, whereas the others capture the objective of price stability in formulating monetary policy in this area). Accordingly, a contraction is associated with an increase in interest rates, a decline in money, an appreciation of domestic currency, and a decrease in prices. They found that monetary policy shock is not a dominant driver of output, implying that accounting for national information on inflation and output gap is essential to improve the efficiency of monetary policy conduct in selected economies.

The sign methodology of Uhlig (2005) showed the merit of capturing complex setting of monetary policy for not only the countries where exchange rates are floating but also small-open economies with the managed exchange rate regime. Given Ho and Yeh (2010), who studied monetary policy effect in Taiwan, sign restrictions are placed on both interest rates and foreign reserves (rather than exchange rates or exchange rate depreciation as in previous studies). As suggested, monetary authorities in this country frequently intervened in the exchange market to stabilize the value of domestic currency. As a result, monetary policy could operate through both interest rates and the stock of foreign reserves. In other words, a restrictive monetary shock combined a rise in interest rates with a fall in the stock of foreign reserves. The study provides impulse response without any puzzles, which was contrast to the shortcomings found as per Cushman and Zha (1997)'s and Berument (2007)'s strategies.

This study also employs the recently developed sign restriction VAR, for investigating the effect of monetary policy in Vietnam, where the operating procedure of monetary policy is much more complicated than that in other countries. Unlike the techniques as applied by Uhlig (2005) and Ho and Yeh (2010), monetary policy shocks are identified through unexpected changes in policy rates, broad money, and state bank credit since these instruments are easily influenced by the State Bank of 
Vietnam. The stock of foreign exchange reserves is also included to reflect the objective of exchange rate stability.

\section{Methodology}

There are several strategies to estimate model (1) in the literature (see below). One is to use the recursive scheme with a Cholesky decomposition, and another is to use non-zero-restriction on either short- or long-run coefficients (Sims, 1980). However, in most cases these restrictions lead to results inconsistent with economic theories (Canova \& Pina, 2000), such as exchange rate puzzle (Sims, 1992; Grilli \& Roubini, 1995, 1996) and delayed overshooting puzzle (Clarida \& Gali, 1994; Grilli \& Roubini, 1995, 1996; Kim, 2001, 2005).

Instead, we can analyze the monetary policy effect on output, prices, and other macroeconomic variables by assigning a prior assumption on the signs of the selected shocks in a VAR model, which is based on both economic theories and practical behavior of monetary authorities (Uhlig, 2005). Unlike the strategy of Uhlig (2005) and those of previous studies, this paper accounts for not only the interaction of dubious policy, including monetary policy and exchange intervention policy, but also the nature of a small open economy with a peg regime.

\section{$V A R$ with sign restriction}

A VAR model has the following specification:

$$
Y_{t}=B_{1} Y_{t-1}+B_{2} Y_{t-2}+\ldots+B_{p} Y_{t-p}+u_{t}
$$

where $Y_{t}$ is an $\mathrm{n} \times 1$ vector of macroeconomic variables and policy variables, $B_{i}$ are $\mathrm{n} \times \mathrm{n}$ matrices of coefficients, and $u_{t}$ is the error matrix with variance-covariance matrix $\Sigma$. According to the literature, the matrix $u_{t}$ can be defined in terms of some structural shocks:

$$
u_{t}=A v_{t}
$$

where $A$ is a n x n matrix of structural parameters and $v_{t}$ is the structural shocks that has zero mean and a variance of unit. Therefore, the variance and covariance can be written as:

$$
\sum=E\left(u_{t} u_{t}^{\prime}\right)=A E\left(v_{t} v_{t}^{\prime}\right) A^{\prime}=A A^{\prime}
$$

The matrix $A$ requires at least $\mathrm{n}(\mathrm{n}-1) / 2$ restrictions to be exactly identified. In order to recover structural shocks, restrictions are imposed on model coefficients by either using a Cholesky decomposition or applying zero restrictions to short- or long-run coefficients. The sign restriction, on the other hand, is based on the prior belief that selected variables do not increase or decrease for a certain period following a specific shock. 
In order to recover the vector of structural shocks, it is essential to obtain an impulse vector of size $\mathrm{n}, a$, as follows:

$$
\begin{aligned}
& A A^{\prime}=\Sigma \\
& a=A \alpha
\end{aligned}
$$

where $\alpha$ is a $\mathrm{n} \times 1$ vector of unit length and $A A^{\prime}=\Sigma$ is a Cholesky decomposition of $\Sigma$.

Next, the response vector derived from the OLS estimation of unrestricted VAR with a Cholesky decomposition is multiplied by the vector $\alpha$ as defined above. The impulse response functions are checked to ensure that the imposed signs are matched.

Uhlig (2005) suggested two approaches to find the sign-matched impulse response functions. The first is the rejection method contingent on the acceptance and rejection of a sub-draw for the vector $a$, which implies equal treatment of all sign-matched impulse response functions. In this paper the second, termed as the penalty function, is preferable since it minimizes the criterion function of sign restriction violation. This approach seeks to obtain an impulse response function that matches the sign restriction as much as possible.

\subsection{Identification of policy shocks}

Table 1 indicates the identification of monetary policy shocks and foreign exchange intervention shocks. Although the literature has widely identified a contraction in monetary policy by positive shocks to short-term interest rates, the identification is not appropriate in Vietnam. It is mainly attributable to the use of multiple instrument framework in Vietnam. Unlike developed economies, Vietnam lacks a well-functioned money market; the SBV, hence, has to directly provide credit for certain banks to solve liquidity problems in numerous occasions. Moreover, this instrument is also used to accomplish fiscal goals. Furthermore, foreign exchange policy is of great importance because of the small and open nature of the Vietnamese economy. As opposed to many countries, Vietnam does not adopt a floating regime, but instead a pegged one. To cope with considerable inflows of foreign capital and remittances, foreign exchange reserves are frequently accumulated in order to keep the foreign exchange stable. However, such interventions lead to an increase in money supply, which is not likely to be fully sterilized by monetary policy. In other words, monetary policy stance could vary because of exchange interventions. Taken all together, a contraction in monetary policy would not cause a fall in policy rates and a rise in central bank credit, foreign exchange reserves, and broad money. 
It must be stressed that the monetary policy identification is distinguished from that of Berument (2007), whereby central bankers can decrease liquidity by either increasing interest rates at a given depreciation level or buying domestic currency while keeping interest rates unchanged. This strategy is less valid in an economy where exchange rates are heavily managed (Ho \& Yeh, 2010). In Vietnam monetary authorities tend to keep exchange rates fixed at certain levels while adjusting monetary policy instruments such as interest rates, broad money, or central bank credit. Therefore, shocks to foreign exchange reserves are critical signals for making decisions on monetary policy. In a similar fashion to Ho and Yeh (2010), it is believed that a monetary contraction is also associated with a fall in foreign exchange reserves. Given sign restrictions, a monetary contraction does not cause an increase in foreign exchange reserves. This prior assumption is essential for capturing the actual contraction in monetary policy.
However, the identification approach in this paper is different from that of Ho and Yeh (2010) since policy rates rather than short-term interest rates are used to access the stance of monetary policy. This is mainly because policy rates are completely controlled by the State Bank of Vietnam. Compared to Taiwan, financial markets are less developed in Vietnam, thus preventing monetary authorities from taking measures to influence the movement of market interest rates on a timely basis.

Moreover, unlike previous studies, shocks to central bank credit are also included to define restrictive monetary shocks. Since monetary authorities have little control over short-term interest rates, they rely on loans to provide additional liquidity to certain banks during emergent situations. This type of credit can also be allocated to specific economic sectors like farming as directed by the government. Therefore, the inclusion better reflects the practice of monetary policy operation in Vietnam. 


\section{Table 1}

Identification of monetary policy and exchange rate policy shocks

\begin{tabular}{|c|c|c|c|c|c|c|c|c|c|}
\hline & 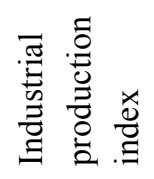 & 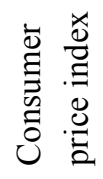 & 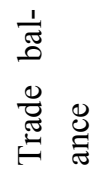 & 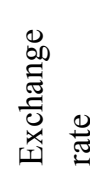 & $\begin{array}{l}\stackrel{x}{\tilde{e}} \\
. \Xi\end{array}$ & 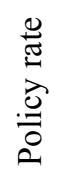 & 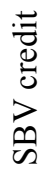 & 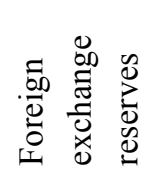 & $\begin{array}{l}\overrightarrow{0} \\
\stackrel{0}{0} \\
\stackrel{0}{0}\end{array}$ \\
\hline $\begin{array}{l}\text { Monetary } \\
\text { policy } \\
\text { shock }\end{array}$ & $?$ & $?$ & $?$ & $?$ & & + & - & - & - \\
\hline $\begin{array}{l}\text { Exchange } \\
\text { rate inter- } \\
\text { vention } \\
\text { shock }\end{array}$ & $?$ & $?$ & $?$ & $?$ & & $?$ & $?$ & + & $?$ \\
\hline
\end{tabular}

Notes: +/- means that the variables do not decrease/increase following a specific shock whereas ? denote the variables which are left unrestricted.

There are several reasons for leaving the impulse response of output and prices (represented by industrial production index and consumer price index respectively) determined by the data. On one hand, it is necessary to examine the effect of monetary policy on its ultimate goal of increasing output. On the other hand, the central bank of Vietnam has neither explicit nor implicit commitment to price stability objectives, which is completely different from that made by the central banks in such developed countries as the United States or European Union members. As a consequence, it is of interest to capture the effectiveness of monetary policy in controlling inflation in Vietnam. Moreover, foreign exchange interventions lead to a likely increase in money supply as well as a persistent pressure of inflation. In short, there is no sign restrictions imposed on output and prices in the analysis.

The impulse response of trade balance and exchange rates is also left unrestricted since there is a need to check whether the identification strategy can resolve puzzles in the interaction between exchange rates and monetary policy in the literature.

Since Vietnam adopts a pegged exchange rate regime, under which the exchange rate was previously pegged to the US dollar and then a basket of 8 currencies in early 2016, the stock of foreign exchange is frequently changed to stabilize the supply of and demand for foreign exchange and keep exchange rates stable. Therefore, innovations in monetary policy instruments are not important to the setting 
of foreign exchange intervention policy. Indeed, in this study the exchange rate policy shock is identified by shocks to only foreign exchange reserves.

The identification of both monetary policy and exchange rate policy is summarized in Table 1. In order to capture the monetary policy shock, sign restrictions are put on policy rates, state bank credit, money supply, and foreign exchange reserves, whereas others are left unrestricted. Meanwhile, shocks to exchange policy are just limited to innovations in foreign exchange reserves.

\subsection{Data}

The VAR model in this paper consists of 8 endogenous variables. Four variables used to assess monetary policy shocks comprise policy rate, foreign exchange reserves, state bank credit, and broad money. Industrial production index and consumer price index are business cycle variables that are intensively adopted to represent output and prices in the literature.

It should be noted that the industrial production index is derived from two sources. The first part of the series, which spans over the period between January 2001 and December 2012, is retrieved from the website Asia Regional Integration Center. The remaining part until April 2016 is derived from the General Statistics Office of Vietnam. Both are modified to be calculated on the same base year of 2010. Other variables are collected from the International Monetary Funds (IMF) and also span from January 2001 through April 2016.

Table 2 provides some basic statistics of these variables, each of which contains 184 monthly observations. As observed, the policy rate has the mean of $7.3 \%$ and fluctuates from the low of 4.5 to $15 \%$. Over the period, the money supply M2 shows a gradual increase to the high of VND5771.4 trillion (April 2016) - 27 times more than the figure in January 2001. With respect to the credit that banks have received from the $\mathrm{SBV}$, the amount is considerable, averaging at VND53.4 trillion per month (with a peak of VND307.6 trillion by January 2011). Foreign exchange reserves have the mean of 12151.1 and the standard deviation of USD5817.9 million. The foreign exchange index moves in a very narrow range from 88.9 to 119.4 , which stands in contrast to the flexible movement of foreign exchange reserves. A few measures of real activities such as industrial production index and trade balance are subject to strong fluctuations.

For econometric purposes, all variables except for the policy rate are presented in the natural logarithm form. 


\section{Table 2}

Statistical description

\begin{tabular}{lcccccc}
\hline Variable & Unit & Obs. & Mean & $\begin{array}{c}\text { Std. } \\
\text { dev. }\end{array}$ & Min. & Max. \\
\hline Policy rate (\%) & $\%$ & 184 & 7.3 & 2.8 & 4.8 & 15.0 \\
Money supply & VND trillion & 184 & 1964.3 & 1698.0 & 208.4 & 5771.4 \\
SBV credit & VND trillion & 184 & 53.4 & 59.2 & 8.0 & 307.6 \\
Foreign exchange reserves & USD million & 184 & 12151.1 & 5817.9 & 3329.0 & 26434.7 \\
Consumer price index & $\%$ & 184 & 91.2 & 36.1 & 47.6 & 145.4 \\
Industrial production index & $\%$ & 184 & 83.6 & 37.3 & 20.5 & 164.7 \\
Foreign exchange index & $\%$ & 184 & 107.8 & 10.0 & 88.9 & 119.4 \\
Trade balance & \%SD million & 184 & -478.6 & 716.5 & -3256.7 & 1444.0 \\
\hline
\end{tabular}

\section{Empirical results}

\subsection{Empirical evidence from impulse response analysis}

Figure 1 plots the responses of macroeconomic variables to a restrictive monetary shock, which is estimated by the penalty method of Uhlig (2005). As indicated, there are three lines for each impulse response plot. The median response is in the middle while the upper and lower lines are 16 th and 84th percentiles of the posterior distribution of 10,000 draw samples respectively. The choice of 16 th and 84 th percentiles indicates a one standard deviation confidence interval (Rogers, 1999), which is the standard representation in the sign restriction literature (Gambacorta et al., 2014). The figure shows that when monetary authorities implement tightened monetary policy, policy rates show an impact increase, lasting for about 8 months before reducing. Meanwhile, foreign exchange reserves immediately decrease, reaching a trough around the third month and then bouncing back. On the other hand, central bank credit significantly reduces on impact but increasing quickly after 3 months. Money supply exhibits a permanent decrease following a contraction in monetary policy. It must be stressed that the response of these four variables are restricted by construction for identifying a restrictive monetary shock. 
The emphasis here is on the impulse response function of unrestricted variables such as output, prices, exchange rates, and trade balance. Following a positive shock to monetary policy, prices show a persistent decreasing response, reaching the lowest level after about one and a half year. Thereafter, the negative response persists until the 30th month. The impact increase in prices provides evidence of price stickiness in Vietnam. It implies that firms do not adjust prices at a higher frequency when macroeconomic environment changes. One reason is the weak competition in the market; hence, firms are not under pressure to reduce prices to compete with others. The price responses are, to a great extent, contrast with the insignificant or temporary effect of monetary policy on inflation found in previous studies such as Bhattacharya (2014) or Hung and Pfau (2009).

On the contrary, output, which is represented by industrial production index, shows a noisy pattern of movement in the first few months. It reveals an impact fall, rising in the next few months and then exhibiting a permanent and significant reduction up to 18 months. The negativity in the response of output is plausible and well-supported by previous studies in Vietnam (e.g., Hung \& Pfau, 2009; Bhattacharya, 2014; Thu Thuy Vinh, 2015).
Interestingly, in a few months after a contraction in monetary policy, output exhibits positive responses, which suggests unexpected changes in the expectation of agents. The phenomenon provides evidence of the adverse effect of monetary policy in emerging country, which was mentioned in the study of Maćkowiak (2007). In an economy where the problem of information asymmetry is severe and the private sector is likely to assume that central bankers may have unavailable information on economic conditions, the stance of monetary policy works as an informative signal about the performance of the economy in the future. In the short run, partially irrational agents may quickly update their expectation and behavior in accordance with policy decisions, which counteracts the effects of the intended policy. In the long run, they are more certain about the stance of monetary policy and thus reverse their expectation and behaviors. Afterward, the restrictive monetary policy shows its intended effects, leading to a decline in output. For those reasons, improving the transparency of the central bank's operations would increase the efficiency of monetary policy in the short run.

The identification indicated in Table 1 has an ability to resolve some puzzles in the VAR literature of monetary policy analysis. In particular, the empirical results show no evidence of the liquidity 
puzzle, whereby prices tend to rise after a tightening decision. Instead, a monetary contraction causes a persistent decrease in prices, which is in agreement with conventional conceptualization.

Considering exchange rates, they show no significant responses to monetary policy changes until the 9th month. Although
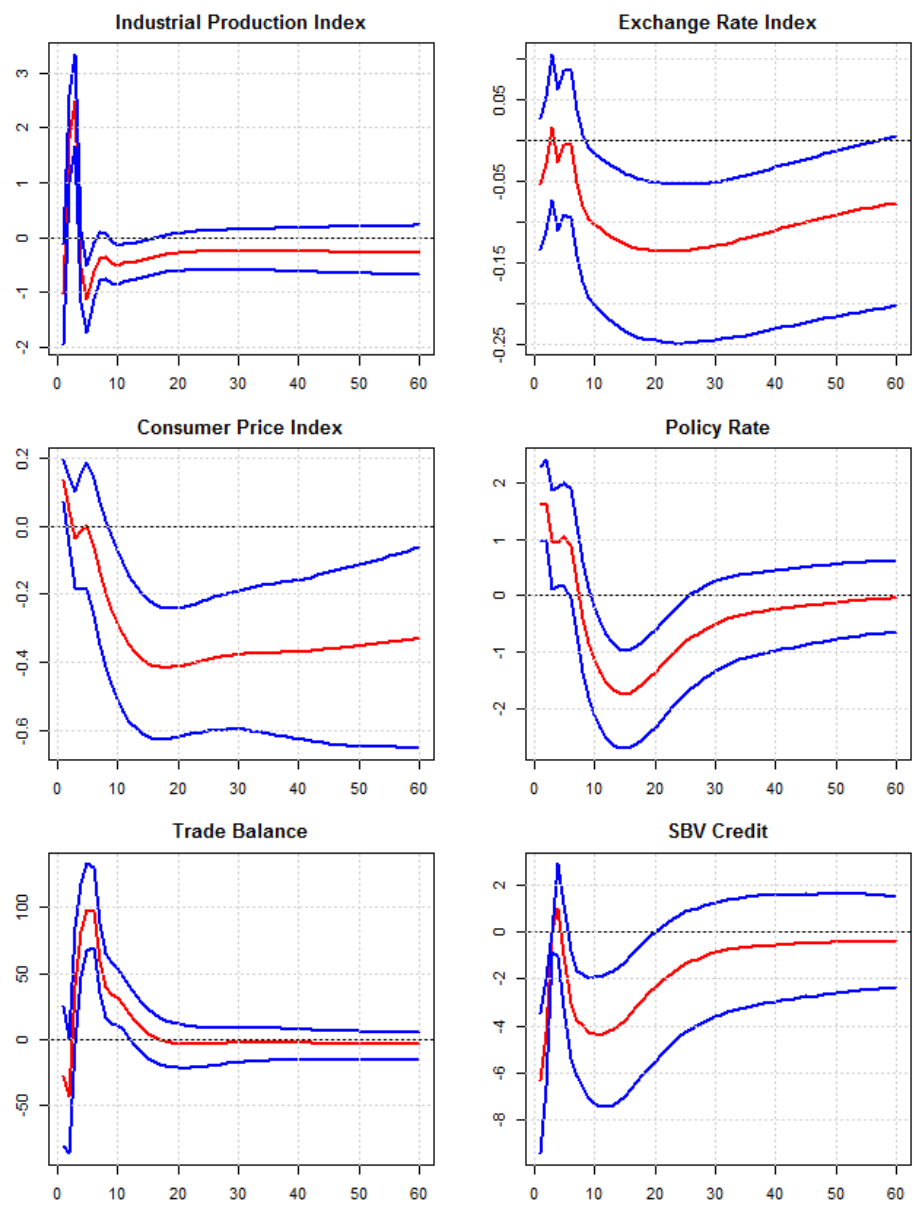
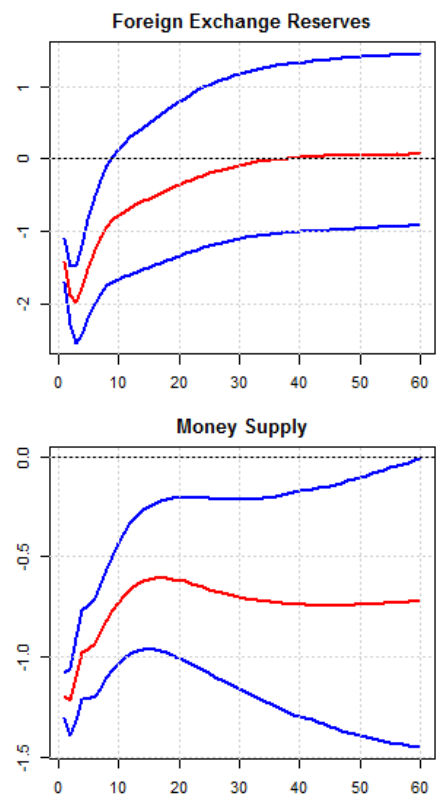
(Dornbusch, 1976), which states that exchange rates appreciate initially and depreciate subsequently, such a response is reasonable if the nature of the pegged regime is taken into account.

Figure 1. Responses of macroeconomic variables to positive monetary policy shock 
Figure 2 shows the impact of foreign exchange interventions on a number of macroeconomic variables. A positive intervention shock means a purchase of foreign currency, which results in an increase in liquidity and a depreciation of domestic currency. As observed, exchange rates show a temporary depreciation and subsequent appreciation, which is in line with the standard prediction.

In addition, the SBV makes a great effort to sterilize the effects of foreign exchange interventions. From Figure 2 policy rates increase immediately after a positive shock to foreign exchange reserves. This lasts for a short period of five months. Moreover, monetary authorities tend to cut back on loans to reduce liquidity injected by purchase interventions in the foreign exchange market. The declining trend persists for a few months until the reverse takes place. These actions cause an appreciation of domestic currency, which alleviates the foreign exchange intervention effects. The significant response of exchange rates implies that the sterilization attempts are too strong, causing an appreciation until the 5 th month. This obviously leads to a reduction in trade balance and output.

Prices, in addition, show a considerable and significant increase in the long run. In fact, an enormous amount of capital flows into Vietnam, which may arise from either the policy on attracting foreign direct investment or remittances from overseas $\mathrm{Vi}$ etnamese. To prevent nominal appreciation, the central bank tends to acquire the excessive supply of foreign currencies in the market, which is conducive to an increase in money supply and an expectation of high inflation in the future.

\subsection{Empirical evidence from the anal-} ysis offorecast error variances decomposition

Variance decomposition is useful to verify the suitability in identifying monetary policy shocks. In this paper, posterior variance decomposition is used to examine the importance of policy shocks to the variance of economic variables. Table 3 depicts the forecast error variances decompositions from the first 1 to 30 months ahead in a variety of variables. As can be seen, monetary policy shocks explain a large proportion of the variance of broad money and foreign exchange reserves, roughly $34 \%$ and $25 \%$ respectively in the first quarter. The explanatory power is quite comparable since the 30th month, standing at approximately $12 \%$. For policy rates and SBV credit, such explanatory power is relatively stable, fluctuating around $7.5 \%$ and $9 \%$ respectively. However, monetary shocks explain only a small percentage of the variation of trade balance and exchange rates in the short 
run, but the contribution gradually in- whereas their contribution to price fluctucreases to approximately 7\%. They ac- ation increases from 6.57 to more than count for a large part of output movement, $11 \%$.

stabilizing at $8.4 \%$ for the whole horizon,
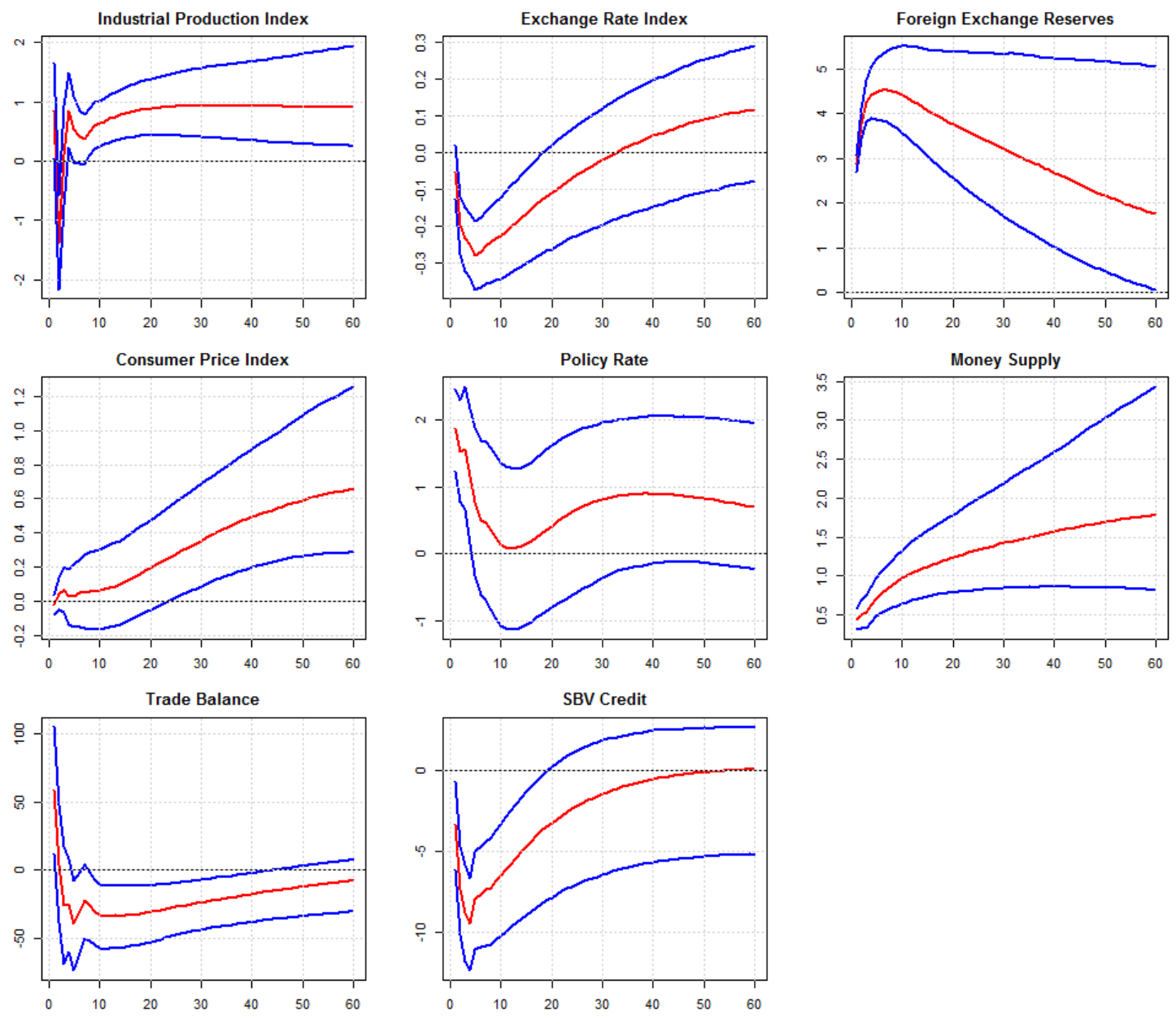

Figure 2. Responses of macroeconomic variables to positive exchange rate policy shock 


\section{Table 3}

Variance of variables according to monetary policy shock

\begin{tabular}{|c|c|c|c|c|c|c|c|c|}
\hline$\stackrel{\mathscr{\Xi}}{\Xi}$ & 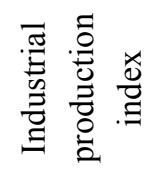 & 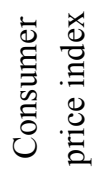 & 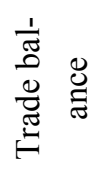 & 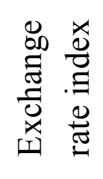 & 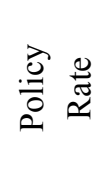 & $\begin{array}{l}:= \\
0 \\
0 \\
0 \\
0 \\
0\end{array}$ & 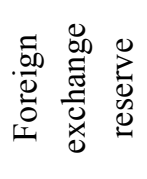 & 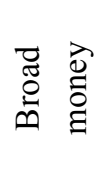 \\
\hline 3 & 8.42 & 6.57 & 2.55 & 3.63 & 7.61 & 9.19 & 24.51 & 33.98 \\
\hline 6 & 8.66 & 7.21 & 5.87 & 4.45 & 7.26 & 9.21 & 19.80 & 26.23 \\
\hline 9 & 8.53 & 8.43 & 6.39 & 4.93 & 7.32 & 9.40 & 17.05 & 20.83 \\
\hline 12 & 8.46 & 9.51 & 6.54 & 5.38 & 7.73 & 9.51 & 15.46 & 17.63 \\
\hline 15 & 8.41 & 10.39 & 6.61 & 5.71 & 8.04 & 9.49 & 14.38 & 15.70 \\
\hline 20 & 8.38 & 11.12 & 6.77 & 6.12 & 8.16 & 9.35 & 13.16 & 14.06 \\
\hline 30 & 8.46 & 11.29 & 6.99 & 6.62 & 7.97 & 9.03 & 11.89 & 12.68 \\
\hline
\end{tabular}

Table 4 shows how the variance of variables is explained by foreign exchange intervention shocks. In fact, the variation in foreign exchange reserves is mainly attributed to innovations in itself. It is quite understandable because of the adoption of a pegged regime in Vietnam over the sample horizon. In the first three months, more than $60 \%$ of the volatility of this variable is explained by its own shocks, which reduces a little to about $45 \%$ in the next quarter and then gradually decreases to approximately $22 \%$ by the 30 th month. Furthermore, foreign exchange intervention shocks explain a considerable proportion of the variance of variables such as broad money, SBV credit, policy rates, and exchange rate index. However, their explanatory power for trade balance, prices, and output is relatively small, implying that monetary authorities should consider moving toward a more floating regime of the exchange rate. 


\section{Table 4}

Variance of variables according to foreign exchange interventions

\begin{tabular}{|c|c|c|c|c|c|c|c|c|}
\hline$\underset{\boxminus}{\Xi}$ & 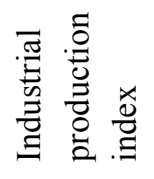 & 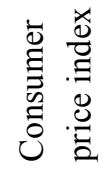 & 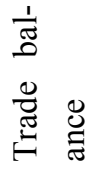 & 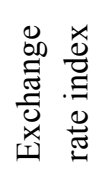 & 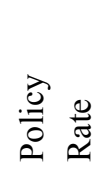 & $\begin{array}{l}:= \\
\stackrel{\Xi}{0} \\
\dot{0} \\
0 \\
0 \\
\infty\end{array}$ & 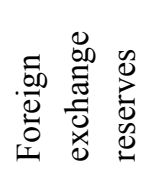 & 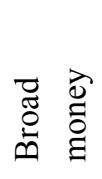 \\
\hline 3 & 3.70 & 1.63 & 2.91 & 6.21 & 7.05 & 7.15 & 62.34 & 6.62 \\
\hline 6 & 4.67 & 1.94 & 4.21 & 7.62 & 5.77 & 8.44 & 48.08 & 7.66 \\
\hline 9 & 4.82 & 2.40 & 4.40 & 7.26 & 5.37 & 8.27 & 40.03 & 8.20 \\
\hline 12 & 5.03 & 2.84 & 4.61 & 6.81 & 5.27 & 8.03 & 34.97 & 8.83 \\
\hline 15 & 5.26 & 3.25 & 4.78 & 6.42 & 5.28 & 7.84 & 31.39 & 9.59 \\
\hline 20 & 5.71 & 3.92 & 5.05 & 6.04 & 5.31 & 7.67 & 27.24 & 10.80 \\
\hline 30 & 6.61 & 5.51 & 5.45 & 6.01 & 5.49 & 7.56 & 22.45 & 12.76 \\
\hline
\end{tabular}

\section{Conclusion}

This paper investigates monetary policy effects in a small open economy where exchange rates are heavily managed. For that purpose, the sign restriction methodology is employed to identify shocks to monetary policy and foreign exchange policy. Unlike previous studies, a monetary policy shock is verified as a combination of an increase in policy rates, a decrease in central bank credit, a fall in the stock of foreign exchange reserves, and a decline in broad money. Foreign exchange intervention, on the other hand, is defined by shocks to the stock of foreign exchange reserves.
The study has several important findings. First, output and prices, which are represented by industrial production index and consumer price index respectively, show a reduction following a contraction in monetary policy, which is in line with standard economic theories. However, it must be stressed that monetary policy is effective since the mid-term. The adverse effect of monetary policy in the short run suggests that it is necessary to improve the transparency of the reaction function of monetary policy. Another noteworthy finding is that the exchange rate is unresponsive to monetary shocks in the short run, which is considered a characteristic of a pegged regime rather than a puzzle. 
The analysis of foreign exchange interventions indicates that purchase shocks have positive effects on money supply and prices. Since the exchange rate policy causes inflationary pressure, monetary authorities should consider the following suggestions. First, it is necessary to shift to a more floating regime so that the monetary policy setting can focus further on economic growth or price stability. Second, fostering the development of financial markets is also helpful because it enhances the absorptive ability of the domestic economy.

\section{References}

Berument, H. (2007). Measuring monetary policy for a small open economy: Turkey. Journal of Macroeconomics, 29(2), 411-430.

Bhattacharya, R. (2014). Inflation dynamics and monetary policy transmission in Vietnam and emerging Asia. Journal of Asian Economics, 34, 16-26.

Canova, F., \& Pina, J. P. (2000). Monetary policy misspecification in VAR models. Economics and Business Working Paper No. 420. Department of Economics and Business, Universitat Pompeu Fabra, Spain.

Clarida, R., \& Gali, J. (1994). Sources of real exchange-rate fluctuations: How important are nominal shocks? Paper presented at the Carnegie-Rochester conference series on public policy, New York University, NY.

Cushman, D. O., \& Zha, T. (1997). Identifying monetary policy in a small open economy under flexible exchange rates. Journal of Monetary Economics, 39(3), 433-448.

Dornbusch, R. (1976). Expectations and exchange rate dynamics. The Journal of Political Economy, 84(6), 1161-1176.

Gambacorta, L., Hofmann, B., \& Peersman, G. (2014). The effectiveness of unconventional monetary policy at the zero lower bound: A cross-country analysis. Journal of Money, Credit and Banking, 46(4), 615-642.

Granville, B., \& Mallick, S. (2010). Monetary policy in Russia: Identifying exchange rate shocks. Economic Modelling, 27(1), 432-444.

Grilli, V., \& Roubini, N. (1995). Liquidity and exchange rates: Puzzling evidence from the G-7 countries. Working Paper Series. New York University, Salomon Center.

Grilli, V., \& Roubini, N. (1996). Liquidity models in open economies: Theory and empirical evidence. European Economic Review, 40(3), 847-859. 0

Ho, T.-K., \& Yeh, K.-C. (2010). Measuring monetary policy in a small open economy with managed exchange rates: The case of Taiwan. Southern Economic Journal, 76(3), 811-826. 
Hung, L. V., \& Pfau, W. D. (2009). VAR analysis of the monetary transmission mechanism in Vietnam. Applied Econometrics and International Development, 9(1), 165-179.

Kim, S. (2001). International transmission of US monetary policy shocks: Evidence from VAR's. Journal of Monetary Economics, 48(2), 339-372.

Kim, S. (2005). Monetary policy, foreign exchange policy, and delayed overshooting. Journal of Money, Credit and Banking, 37(4), 775-782.

Kim, S., \& Roubini, N. (2000). Exchange rate anomalies in the industrial countries: A solution with a structural VAR approach. Journal of Monetary Economics, 45(3), 561-586.

Maćkowiak, B. (2007). External shocks, US monetary policy and macroeconomic fluctuations in emerging markets. Journal of Monetary Economics, 54(8), 2512-2520.

Mishkin, F. S. (2013). The economics of money, banking, and financial markets. Pearson Education, NJ.

Rafiq, M. S., \& Mallick, S. K. (2008). The effect of monetary policy on output in EMU3: A sign restriction approach. Journal of Macroeconomics, 30(4), 1756-1791.

Rogers, J. H. (1999). Monetary shocks and real exchange rates. Journal of International Economics, 49(2), 269-288.

Sims, C. A. (1980). Macroeconomics and reality. Econometrica, 48(1), 1-48.

Sims, C. A. (1992). Interpreting the macroeconomic time series facts: The effects of monetary policy. European Economic Review, 36(5), 975-1000.

Thu Thuy Vinh, N. (2015). The role of different channels in transmitting monetary policy into output and price in Vietnam. Journal of Economics and Development, 17(1), 20-40.

Uhlig, H. (2005). What are the effects of monetary policy on output? Results from an agnostic identification procedure. Journal of Monetary Economics, 52(2), 381-419. 